\title{
SERUM ENZYME ACTIVITY IN THE NORMAL NEWBORN INFANT
}

\author{
BY \\ J. KING and M. BRENDA MORRIS \\ From the Pathology and Paediatric Departments, North Lonsdale Hospital, the Barrow and Furness Hospital Group
}

(RECEIVED FOR PUBLICATION APRIL 14, 1961)

The assay of serum enzymes has been used increasingly in recent years as an aid to clinical diagnosis and prognosis, but the literature contains few references to the exploitation of these laboratory tests in paediatrics.

Following the development in these laboratories of assay procedures for glutamate-oxalacetate transaminase (GO-T), glutamate-pyruvate transaminase (GP-T), lactate dehydrogenase (LDH) and malate dehydrogenase (MDH) suited to routine work, the determination of the normal serum activities of these enzymes in the neonatal period was undertaken in conjunction with an investigation of the usefulness of their estimation in haemolytic disease of the newborn.

The transaminase enzymes form a link between protein and carbohydrate metabolism and mediate in the reactions shown in equations (i) and (ii).

(i)<smiles>NC(CC(=O)[O-])C(=O)CCC(=O)C(=O)C(=O)C(=O)[O-]</smiles>
(aspartate) (a-oxoglutarate) (oxalacetate) (glutamate)

(ii)

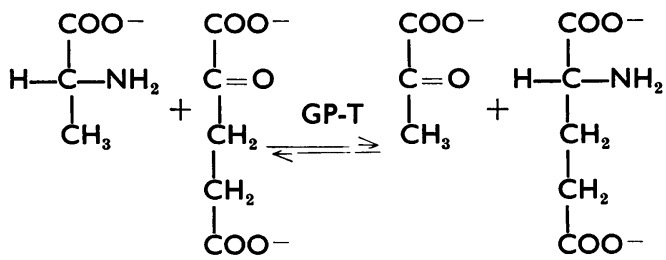

(alanine) (a-oxoglutarate) (pyruvate) (glutamate)

Lactate dehydrogenase is a glycolytic enzyme and malate dehydrogenase catalyses the final step in the tricarboxylic acid cycle. These biocatalysts, as found in human blood serum, require coenzyme I (diphosphopyridine nucleotide-DPN) as hydrogen carrier and exhibit greatest activity in the reactions summarized by equations (iii) and (iv).

(iii)

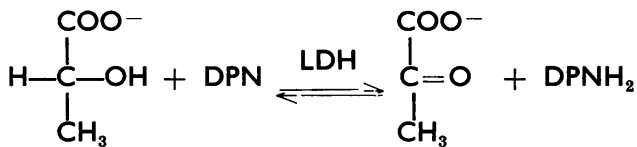

(lactate) (coenzyme I) (pyruvate) (reduced coenzyme I)

(iv)

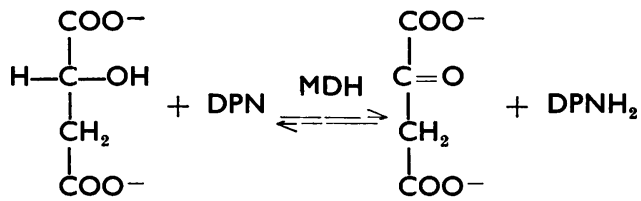

(malate) (coenzyme I) (oxalacetate) (reduced coenzyme I)

\section{Methods and Materials}

Glutamate-oxalacetate transaminase (GO-T) and glutamate-pyruvate transaminase (GP-T) activities were estimated by the methods of King (1960a). As the colorimetric procedures for the assay of serum lactate dehydrogenase (King, 1959, 1960b) and malate dehydrogenase (King, 1961) are rapid and require small quantities of serum they were found to be suited to the present survey.

Bilirubin levels were determined by a micro adaptation of the method of Malloy and Evelyn (1937), checked on numerous occasions when the sample permitted by the spectrophotometric technique of Scott (1959). Good agreement was obtained between the two methods. The latter procedure was found to give an indication of degree of haemolysis which in icteric serum is sometimes difficult to decide by inspection.

The material consisted of 154 cord bloods and 41 specimens of blood taken from normal full-term infants on one occasion during the first nine days of life. Since GO-T and GP-T activities for whole blood are approximately five and three times respectively those of serum, while for LDH and MDH the ratio ranges from 100 to 150 , specimens showing any visible haemolysis were discarded for purposes of dehydrogenase assay and only the slightest haemolysis was tolerated for the determination of transaminase activity. 
TABLE 1

NORMAL CORD BLOOD VALUES

\begin{tabular}{|c|c|c|c|c|}
\hline & Mean & $\begin{array}{l}\text { Standard } \\
\text { Deviation }\end{array}$ & $\begin{array}{c}98 \% \\
\text { Observed } \\
\text { Values }\end{array}$ & $\begin{array}{c}\text { Adult } \\
\text { Range }\end{array}$ \\
\hline $\begin{array}{l}\text { Bilirubin (mg./100 ml.) } \\
\text { GO-T (International units) } \\
\text { GP-T (International units) } \\
\text { LDH (International units) } \\
\text { MDH(International units) }\end{array}$ & $\begin{array}{c}1 \cdot 86 \\
15 \cdot 1 \\
5 \cdot 5 \\
330 \\
52 \cdot 5\end{array}$ & $\begin{array}{l} \pm 0 \cdot 51 \\
\pm 4 \cdot 1 \\
\pm 2 \cdot 5 \\
\pm 82 \\
\pm 13\end{array}$ & $\begin{array}{c}0 \cdot 6-3 \cdot 4 \\
6-25 \\
1 \cdot 3-11 \\
150-590 \\
22 \cdot 5-98\end{array}$ & $\begin{array}{c}<1 \cdot 0 \\
6-18 \\
3 \cdot 5-15 \cdot 5 \\
70-230 \\
10-44\end{array}$ \\
\hline
\end{tabular}

Cord blood was obtained by letting the blood drip from the maternal end of the cut cord into the collecting bottle, and the subsequent specimens from the babies were obtained by puncture of a scalp vein.

All babies in the normal series were full-term babies of birth weight over $5 \mathrm{lb} .8 \mathrm{oz}$. In the case of the 154 babies whose cord bloods were taken, there was no abnormal jaundice in the neonatal period, and in the case of the 41 babies whose blood was taken at some time in the first nine days of life, every baby was personally observed by one of us (M.B.M.) throughout the first 10 days of life, and their course during this time was normal.

In all cases both mothers' and infants' blood groups were determined and in the 41 infants from whom a second blood specimen was obtained the direct Coombs test was negative.

\section{Results}

Cord Blood. The statistical analysis of figures for the normal cord blood serum is presented in Table 1, together with normal adult values obtained using the same methods. The units originally used in this work were those defined by Antebi and King (1958), but recently an international enzyme subcommission has recommended the use of an International Unit (King and Campbell, 1961) for expressing serum enzyme activity and the results obtained in the present study are recorded in International Units. This unit is that which will transform $1 \mu$ mole of substrate per minute under the prescribed assay conditions, activity to be expressed per litre.

Similar to the figures obtained in adults, the distributions of all these cord blood enzyme activities are found to be of the 'log normal' type (Gaddum, 1945) and positively skewed. A normal range in terms of mean and standard deviation cannot be expressed under these circumstances and following the arguments of Wootton and King (1953) the range is best expressed by upper and lower $1 \%$ limits which enclose $98 \%$ of the distribution. Figures falling outside these limits may be regarded as abnormal.

It is seen that for GO-T, LDH and MDH the range of values encountered is wider and higher by a factor 1.5 to $2 \cdot 5$ than the respective figures found in normal adults. GP-T on the contrary was found to have a narrower and lower range. $\mathrm{MDH}$ was found to parallel LDH so closely, the ratio of activities approximating to $1: 6$, that it is not proposed to treat it separately.

Figs. 1 to 3 are scattergrams showing the relation

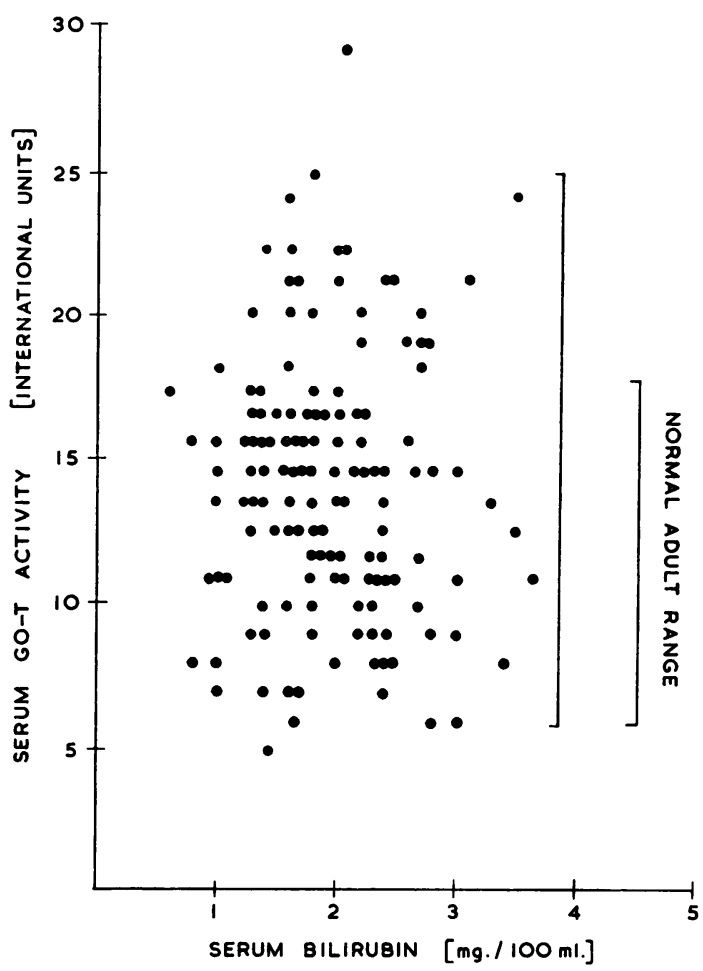

FIG. 1.-Variation of cord GO-T activity with bilirubin.

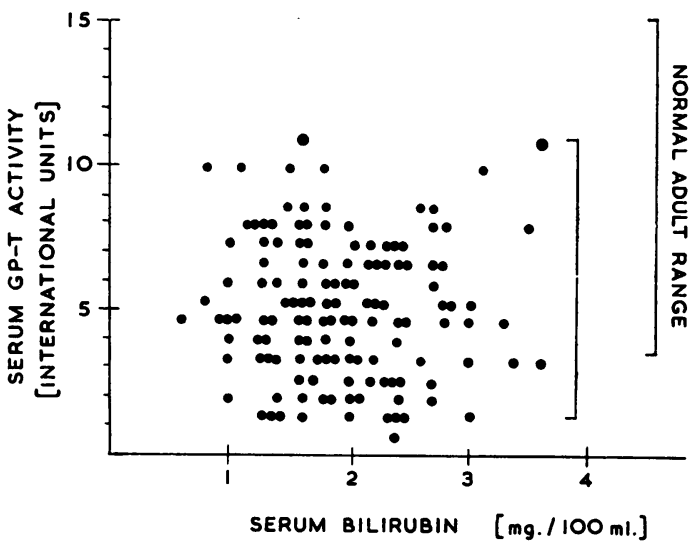

FIG. 2.-Variation of cord GP-T activity with bilirubin. 


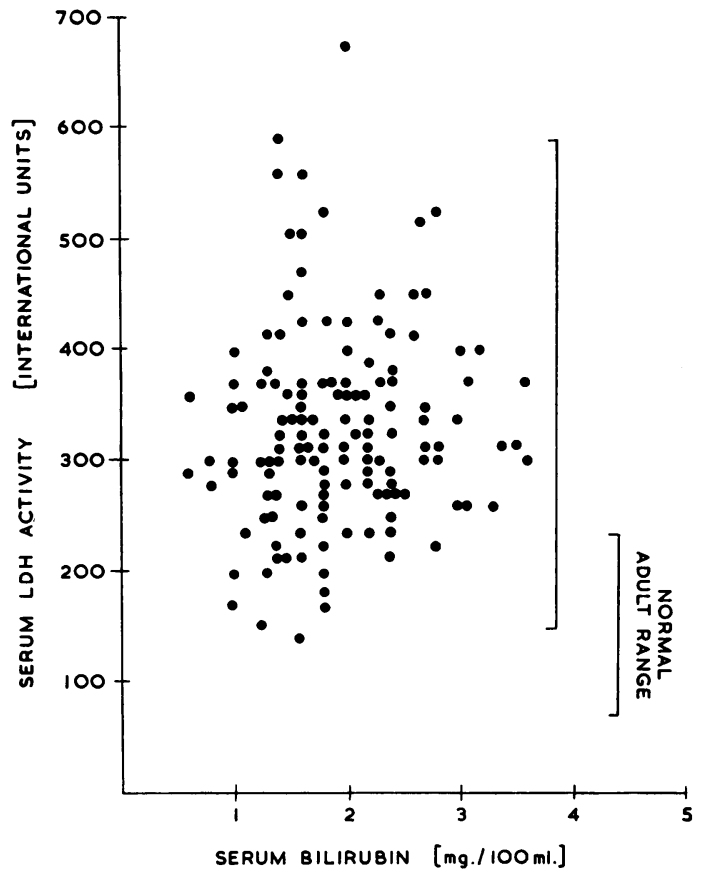

FIG. 3.-Variation of cord LDH activity with bilirubin. between serum enzyme activity and bilirubin levels. These show, not unexpectedly, that there is no correlation between serum bilirubin and any of these enzymes.

No correlation between any of the five biochemical parameters studied, with the exception of LDH and $\mathrm{MDH}$, was found, and no significant difference with sex of the infant could be demonstrated.

The values for normal cord blood GO-T and GP-T activities, together with cord blood figures obtained in some premature infants are shown in Figs. 4 and 5 plotted against gestation period irrespective of birth weight. $\mathrm{LDH}$ and $\mathrm{MDH}$ patterns were similar to that for GO-T inasmuch as all values fell within the normal cord blood range with no obvious change in distribution. GP-T activity, however, did appear to show some decrease with premature delivery, but the number of the sample is too small to demonstrate any significant change.

Normal Newborn Infants. The results obtained from enzyme assays of the 41 'second' specimens, together with the respective cord blood figures are summarized in Figs. 6 to 8 where enzyme activity is plotted against day of life. For GO-T and LDH

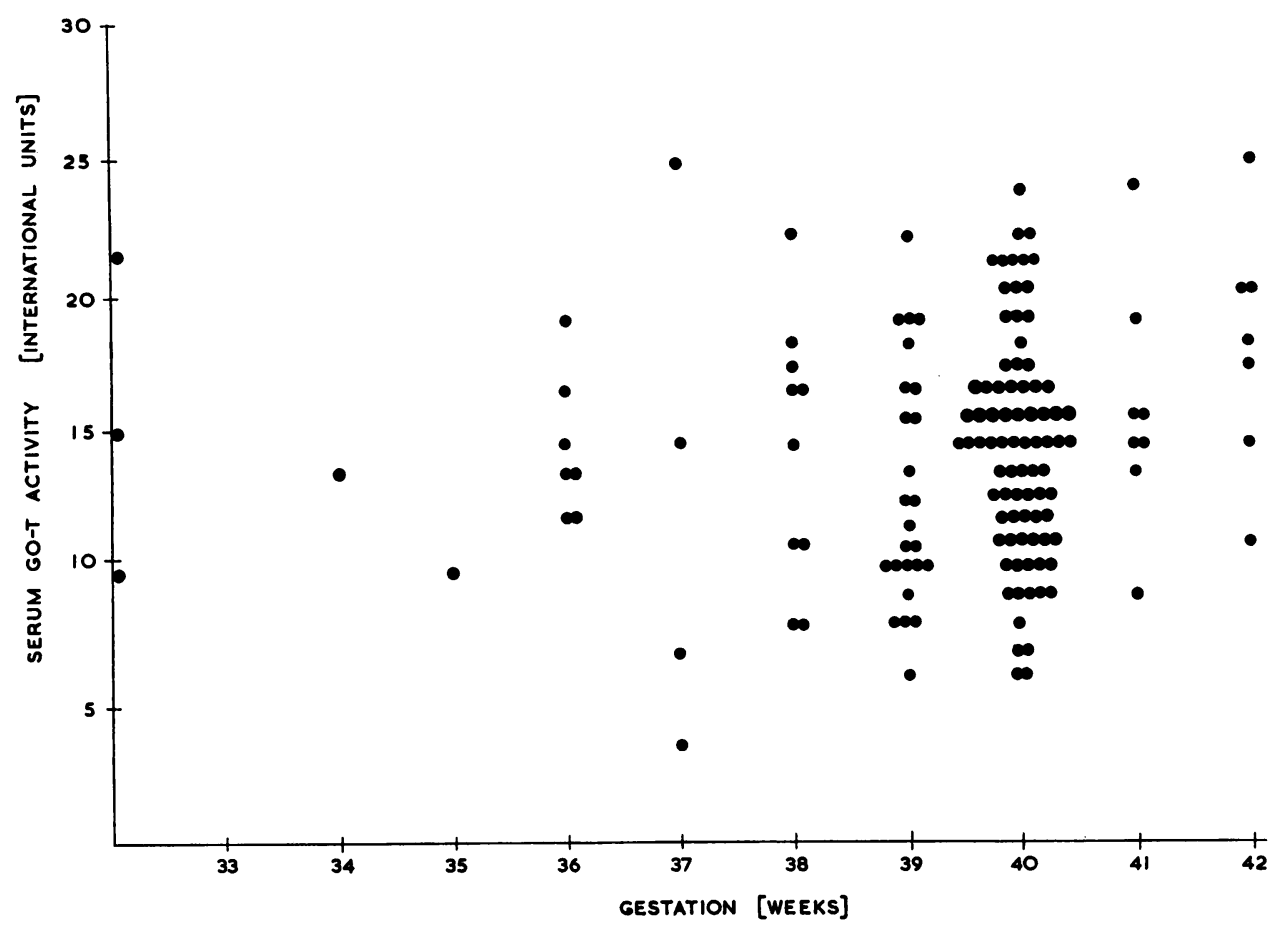

FIG. 4.-Variation of cord GO-T activity with gestation. 


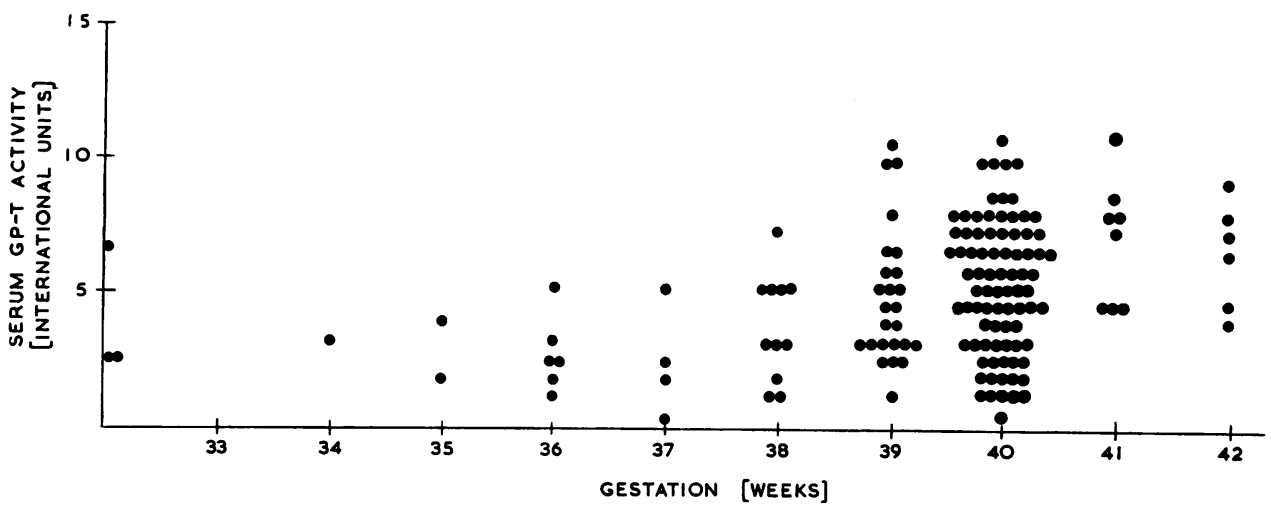

FIG. 5.-Variation of cord GP-T activity with gestation.

and, hence $\mathrm{MDH}$, no variation of enzyme activity was noted either with day of life or with bilirubin level. All figures fell within the range of normal cord blood activity without any obvious significant change in distribution, although the number of the sample is too small for statistical analysis.

Despite this mathematical limitation, however, the increase in GP-T activity with age particularly after the seventh day of life cannot be ignored.

The serum bilirubin figures at this age were found, as expected, to have fallen to low levels, and plotting GP-T activity against bilirubin tends to indicate that there is an inverse proportionality between the two entities, which would be misleading. It is an

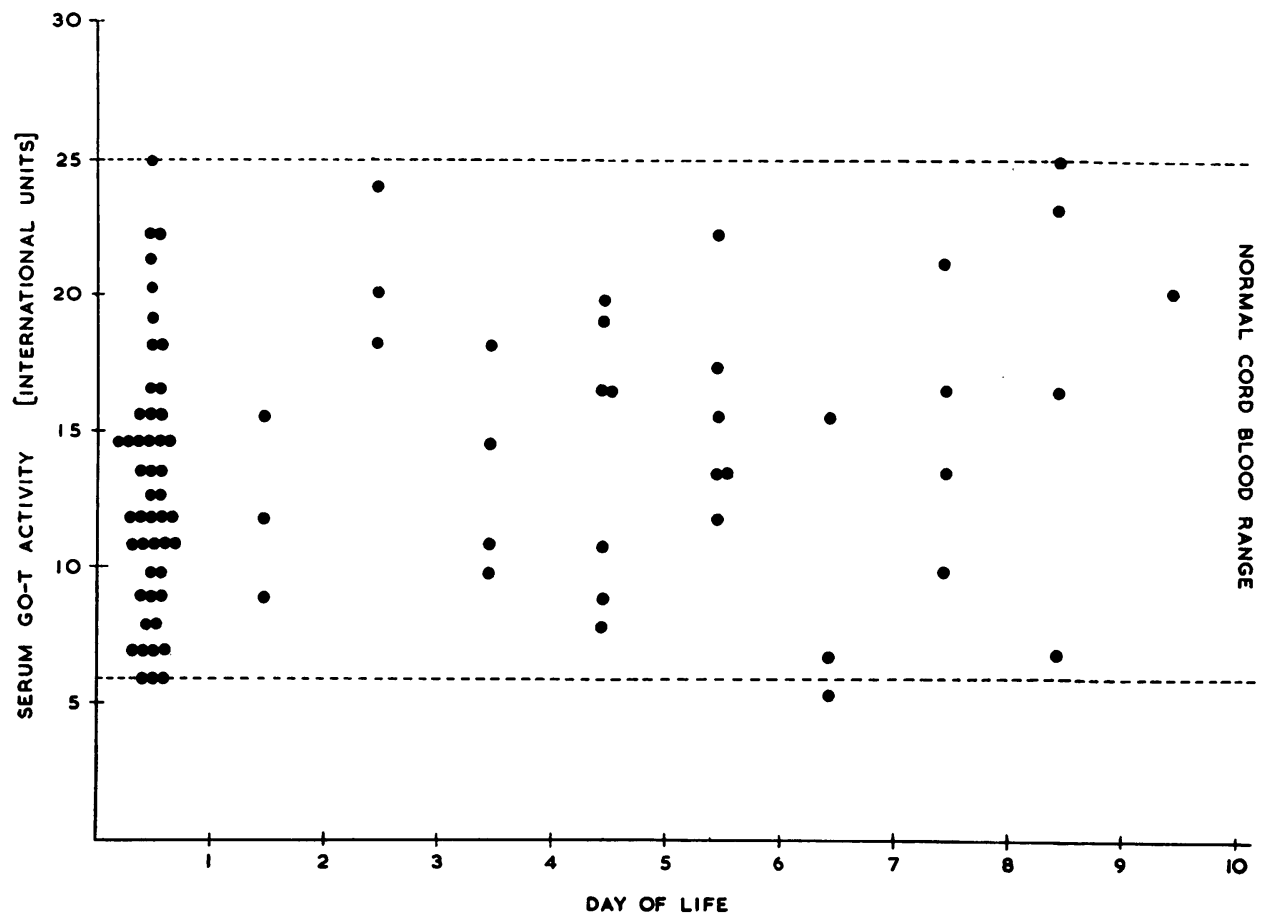

FIG. 6.-Variation of GO-T activity with age. 


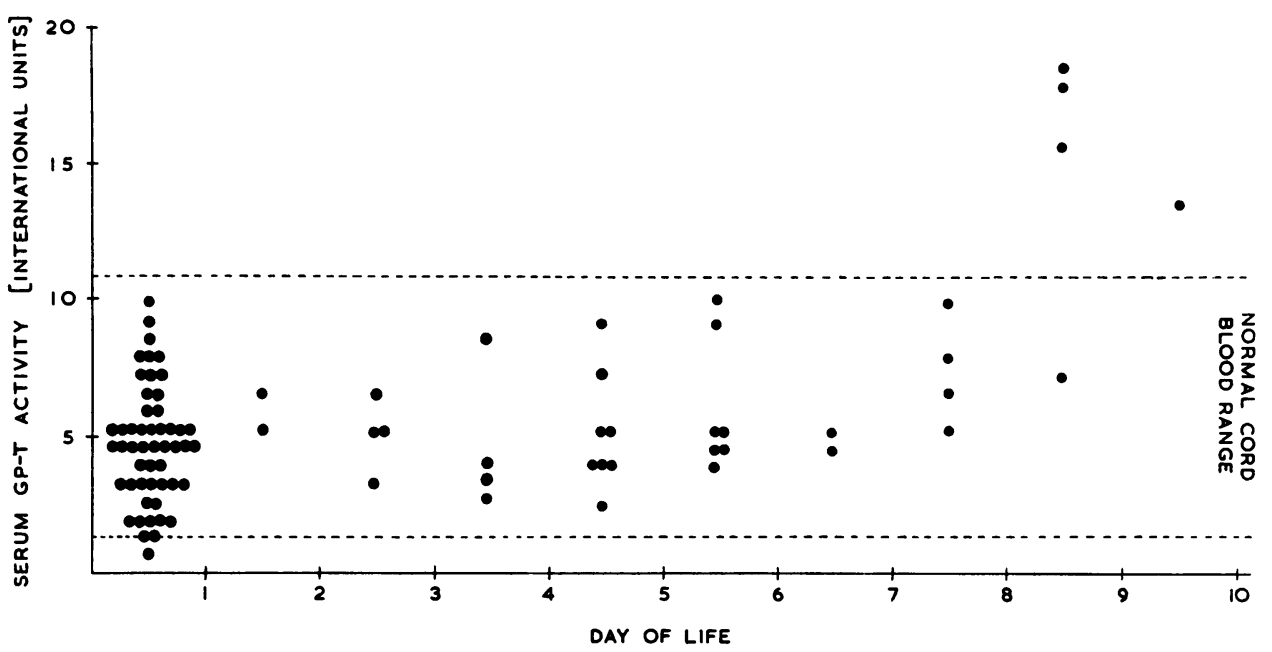

FIG. 7.-Variation of GP-T activity with age.

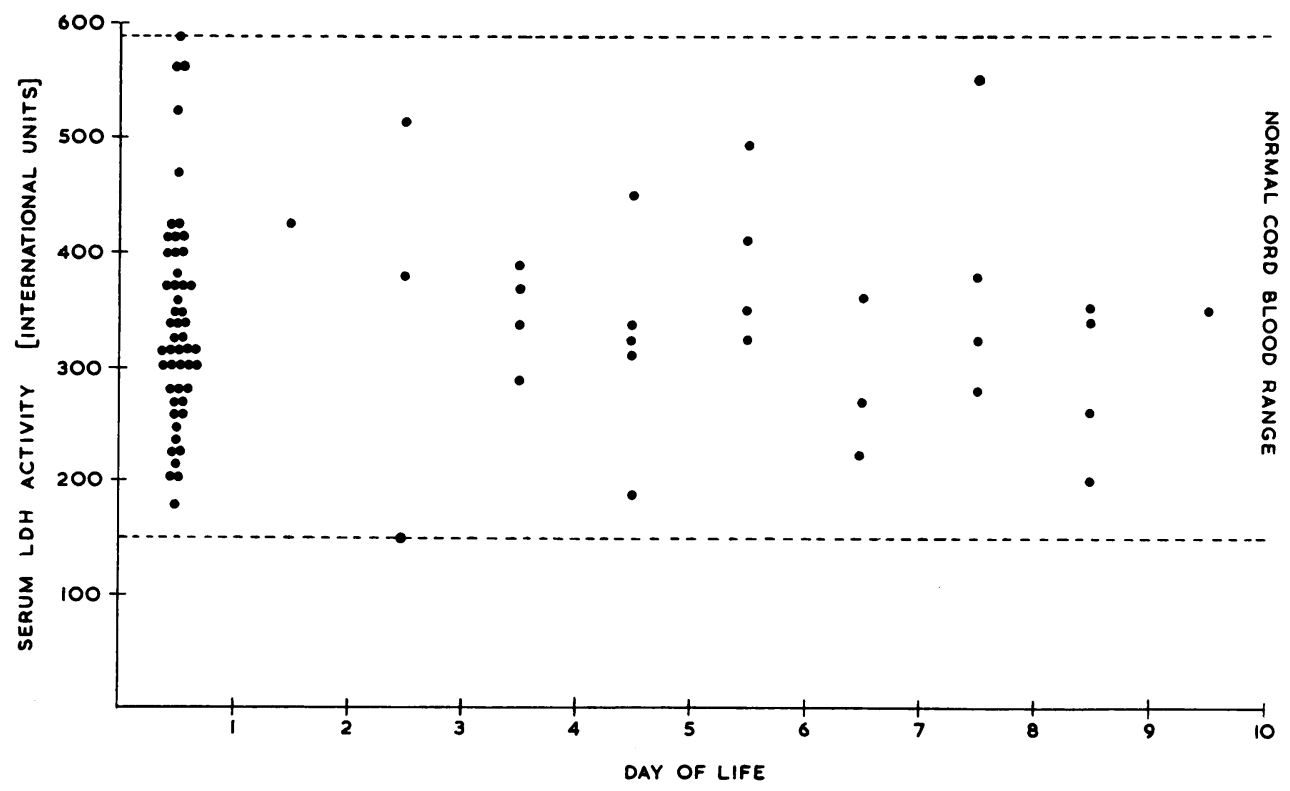

FIG. 8.-Variation of LDH activity with age.

attractive speculation, however, to connect the known decrease in bilirubin levels after the fifth day of life with the increasing activity of GP-T in the serum.

\section{Discussion}

Kove, Goldstein and Wróblewski (1957a, 1957b) assayed GO-T and GP-T from nine normal cord bloods and found values of 20 to 59 units (Karmen, $1955)$ and 12 to 40 units respectively. The adult values by this method were given as 5 to 45 units for GO-T and 5 to 40 units for GP-T, but were later (Kove, Perry and Wróblewski, 1960) modified to 8 to 40 units and 5 to 35 units respectively. A conversion factor of approximately 0.45 transforms Karmen units to those used in this survey, 
whence it will be seen that there is reasonably good agreement for cord GO-T figures.

The values found in the present study for GP-T, however, are lower and the range narrower than those accepted by these workers despite the small number of their sample.

In a further 54 infants aged from 1 to 11 days, values for GO-T from 13 to 105 units (with one of 160 units which was discounted) were encountered, and for GP-T figures from 8 to 80 units were obtained with a peak activity in the fourth to fifth day of life (Kove et al., 1957a and b). These workers included in their normal series five out of nine babies with cord serum bilirubin values over $3 \mathrm{mg} . / 100 \mathrm{ml}$ : Higher values may occur in normal babies, but only rarely (Hsia, Allen, Diamond and Gellis, 1953). In their series also there were three babies with serum bilirubin values of $18 \mathrm{mg}$., $33 \mathrm{mg}$. and $17 \cdot 5$ $\mathrm{mg}$. on the second, third and fourth days respectively. It is very unusual to obtain values higher than $15 \mathrm{mg}$./ $100 \mathrm{ml}$. in normal babies. Hsia et al. (1953) found no value above $14 \mathrm{mg} . / 100 \mathrm{ml}$., and in our normal series we had only one value above $14 \mathrm{mg} . / 100 \mathrm{ml}$., i.e. one sustained level of $17-18 \mathrm{mg}$./100 ml. from the fifth to the tenth day for which we found no cause. While these high levels do occur for no discoverable reason, they seem to be so rare as to suggest that they must, nevertheless, be pathological. Kove et al. (1957a and b) do not appear to have excluded haemolytic disease due to ABO incompatibility in their group of babies. The data for GO-T and GP-T presented in this paper are in disagreement with these earlier figures.

Using the same assay procedure, Stanton and Joos (1959) found lower values ranging from 29 to 72 units in 15 infants from 2 to 6 days of age, and West and Zimmerman (1958) found GO-T activity to be elevated above the upper adult limit of 40 units in four out of 19 cord bloods. The values of these sera were 48, 50, 113 and 114 units. LDH activity assayed on the same 19 sera was found to be twice the adult normal levels with very slight overlap of ranges. Hill (1956) has previously reported higher levels of LDH activity in normal children which approached the adult range at about 14 years of age. Lending, Slobody, Stone, Hosbach and Mestern (1959) in 54 infants from $2 \frac{1}{2}$ to 10 days of age found $\mathrm{LDH}$ activity to be elevated to three times the normal adult level. The present survey agrees with these earlier findings for $\mathrm{LDH}$.
A search of the literature reveals no previous report of $\mathrm{MDH}$ activity in the neonatal period.

\section{Summary}

A study of the activity of the enzymes, glutamateoxalacetate transaminase (GO-T), glutamate-pyruvate transaminase (GP-T), lactate dehydrogenase (LDH) and malate dehydrogenase (MDH) has been carried out on 154 normal cord bloods and on 41 bloods from infants during the first nine days of life. A range of normal values for these enzymes is proposed.

The brief literature on the subject is reviewed.

We are indebted to Dr. J. E. Horrocks and Dr. J. Ward for much helpful advice and criticism and to Mrs. Mary Robinson for secretarial work. Our grateful thanks are also due to the house surgeons and nursing staff at Risedale Maternity Hospital and the technical staff of the Group Pathology Laboratory, without whose willing co-operation this work could not have been undertaken.

REFERENCES

Antebi, R. and King, J. (1958). Serum-transaminase activity• Lancet, 1, 1136.

Gaddum, J. H. (1945). Lognormal distributions. Nature (Lond.), 156, 463.

Hill, B. R. (1956). Some properties of serum lactic dehydrogenase. Cancer Res., 16, 460.

Hsia, D. Y-Y, Allen, F. H., Diamond, L. K. and Gellis, S. S. (1953) Serum bilirubin levels in the newborn infant. J. Pediat. 42, 277.

Karmen, A. (1955). A note on the spectrophotometric assay of glutamic-oxalacetic transaminase in human blood serum. J. clin. Invest., 34, 131.

King, E. J. and Campbell, D. M. (1961). International enzyme units; an attempt at international agreement. 4th International Congress on Clinical Chemistry, p. 185. Livingstone, Edinburgh.

King, J. (1959). A routine method for the estimation of lactic dehydrogenase activity. J. med. Lab. Technol., 16, 265. (1960a). A study of human serum transaminases. Ibid., 17, 1 (1960b). A note on the colorimetric assay of coenzyme I and II dependent enzymes. Ibid., 17, 89.

(1961). A routine method for the estimation of serum malate dehydrogenase activity. Ibid., 18, 168.

Kove, S., Goldstein, S. and Wróblewski, F. (1957a). Activity of glutamic-oxalacetic transaminase in the serum in the neonatal period. Pediatrics, 20, 584.

(1957b). Measurement of activity of transaminase in the serum as an aid in differential diagnosis of jaundice in the neonatal period. Ibid., 20, 590.

Perry, R. and Wróblewski, F. (1960). Diagnosis of neonatal jaundice by patterns of serum transaminase. Amer. J. Dis. Child., 100, 47.

Lending, M., Slobody, L. B., Stone, M. L., Hosbach, R. E. and Mestern, J. (1959). Activity of glutamic-oxalacetic transaminase and lactic dehydrogenase in cerebrospinal fluid and plasma of normal and abnormal newborn infants. Pediatrics, 24, 378.

Malloy, H. T. and Evelyn, K. A. (1937). The determination of bilirubin with the photoelectric colorimeter. J. biol. Chem., $119,481$.

Scott, P. (1959). Personal communication.

Stanton, R. E. and Joos, H. O. (1959). Glutamic-oxalacetic transaminase of serum in infancy and childhood. Pediatrics, 24, 362

West, M. and Zimmerman, H. J. (1958). Lactic dehydrogenase and glutamic-oxaloacetic transaminase in normal pregnant women and newborn children. Amer. J. med. Sci., 235, 443.

Wootton, I. D. P. and King, E. J. (1953). Normal values for blood constituents. Inter-hospital differences. Lancet, 1, 470. 